\title{
THE RELATIONSHIP BETWEen COMMOdity MARKETS AND COMMODity MUTUAL FUNDS: A WAVELET-BASED ANALYSIS
}

\author{
Nikolaos Antonakakis*, Tsangyao Chang***, JunCal Cunado ${ }^{* * * *}$ AND RANGan \\ GUPTA $^{* * * * *}$
}

\begin{abstract}
This paper examines the causal relationship between commodities funds and returns using monthly data for the period May 1997 to August 2015. Given the strong evidence of nonlinearity and structural breaks, we use wavelets to analyse causality between the two variables at both time and frequency domains. Wavelet coherency reveals that these two variables are primarily positively related in the short-run and over the period of 2008 to 2015 . When we investigate the phase differences over this period, we observe that flows have predicted returns over the period of 2008 to 2012, with causality running in the other direction thereafter.
\end{abstract}

Keywords: Commodity returns and flows; Granger causality; Nonlinearity; Time and frequency domains; Wavelet

JEL Classification: C32; C53; Q02

\footnotetext{
* Corresponding author. Webster Vienna Private University, Department of Business and Management, 1020, Vienna, Austria. Email: nikoalos.antonakakis@ webster.ac.at. Tel: +43-1-26992934354. University of Portsmouth, Economics and Finance Subject Group, PO1 3DE, Portsmouth, United Kingdom. Email: nikolaos.antonakakis@port.ac.uk. Tel: +44 (0)239284 4261.

** Department of Finance, College of Finance, Feng Chia University, Taichung, Taiwan. Email: tychang@fcu.edu.tw.

**** University of Navarra, School of Economics, Edificio Amigos, E-31080 Pamplona, Spain. Email: jcunado@unav.es. Juncal Cuñado gratefully acknowledges financial support from the Ministerio de Economía y Competitividad (ECO2014-55496).

***** University of Pretoria, Department of Economics, Pretoria, 0002, South Africa. Email: rangan.gupta@up.ac.za.
} 


\section{INTRODUCTION}

According to the Commodity Futures Trading Commission (CTFC, 2008), the value of index-related commodities futures investments grew from $\$ 15$ billion during 2003 to over $\$ 200$ billion in 2008. Coinciding with this significant increase in investment flows, commodity prices showed an unusual behaviour. First, commodities prices, as measured by the Continuous Commodity Index (CCI), rose an impressive 275\% since 2001 to 2011, against a 25\% increase in overall inflation, while individual commodities experienced even greater prices increases (i.e., crude oil, gold and corn prices rose a $1050 \%$, a $528 \%$ and a $348 \%$, respectively). These sharp increases in commodity prices, together with the following decreases occurred due to the 2008 global financial crisis, significantly increased the price volatility of commodities (Silvennoinen and Thorp, 2013). Finally, commodity prices became more correlated with each other, as well as with stock prices (Tang and Xiong, 2012; Silvennoinen and Thorp, 2013). In fact, prior to 2000s, investments in commodities, due to their null or negative correlation with traditional assets, were used as a diversification and a hedging tool (Babalos et al., 2015).

The concurrence of the rapid growth of commodity index investment with the singular behaviour of commodity markets has opened the debate on whether the commodity prices are still driven by supply and demand factors (Krugman, 2008; Hamilton, 2009; Kilian, 2009) or by excessive speculation due to the so-called "financialization" of the commodities markets (see, for example, Basak and Pavlova, 2016, for a theoretical model on financialization, and Fattouh et al., 2016, for a survey on the empirical literature on speculation in commodities markets). The answer to this question has important policy implications on a wide variety of issues, such as on commodity producers' hedging strategies, investors' investment strategies and 
countries' energy and food policies, which justifies the analysis on the relationship between commodity prices and investment flows carried out in this paper.

The impact of the financialization on commodity prices has been analysed in the literature following two main approaches. First, studies have analysed the synchronization or convergence of the commodity prices followed by the financialization process (Tang and Xiong, 2012; Silvennoinen and Thorp, 2013; Cheng and Xiong, 2014; Fernandez, 2015; Sensoy et al., 2015). However, the results on the impact of financialization are contested. For example, Tang and Xiong (2012), Silvennoinen and Thorp (2013) and Cheng and Xiong (2014) find that as a result of the financialization process, commodity futures prices have become increasingly correlated and suggest that commodity prices are mainly determined by the investors' behaviour. On the contrary, Sensoy et al. (2015) analyse the dynamic comovement of commodity futures returns from 1997 to 2013 and conclude that the main driving forces of the commodity futures price dynamics are the supply/demand factors rather than global financial conditions. Second, the impact of the financialization on commodity prices has also been analysed by examining the causal relationship between commodity prices and investment flows (Irwin and Sanders, 2010). In this paper, we follow the second approach and study the causal relationship between commodity prices and investment flows, using a wavelet-based analysis.

The causal relationship between investment flows and stock returns had been extensively studied in the literature before the financialization of the commodities markets observed in the 2000s (Ippolito, 1992; Warther, 1995). Although most of the empirical literature found a positive and significant correlation between the two variables, this result can be interpreted in different ways; depending on the direction of the causal relationship. First, the relationship between these variables can be explained 
by the "smart money" hypothesis (Grubber, 1996; Zheng, 1999; Edelen and Warner, 2001; Levy and Lieberman, 2016) if investment flows are directed towards products with higher returns. Second, and following the financialization hypothesis, some papers test for causality from investment flows to returns (Warther, 1995; Irwin and Sanders, 2010; Levy and Lieberman, 2016). The literature offers two explanations of why fund flows may affect returns: information revelation (Warther, 1995) and price pressures and investor sentiment (Shleifer, 1986). Finally, a bidirectional causal relationship between the two variables is used in the literature to explain the "spiralling" commodity prices observed in the last years (Basak and Pavlova, 2016) due to the inflow of institutional investors into the futures commodities market.

The empirical results on the direction of the causal relationship between fund flows and returns are not conclusive. For example, Warther (1995) finds evidence of a significant positive relationship between weekly aggregate fund flows and subsequent returns in the US, while this relationship does not hold when he uses monthly data. Remolona et al. (1997) study the bidirectional causal relationship between aggregate fund flows and returns in the US, finding no significant relationship between the two variables. Evidence in favour of the "smart money" hypothesis is found in Grubber (1996), Edward and Zheng (1998), Zheng (1999), Edelen and Warner (2001) and Levy and Lieberman (2016) for the US market, in Oh and Parwada (2007) in Korea, and in Watson and Wickramanayake (2012) in Australia, among others. Edelen and Warner (2001) study the relation between market returns and aggregate flow into US equity funds using daily flow data and find that aggregate flow follows market returns with a one-day lag. On the other hand, Mosebach and Najand (1999) provide evidence in favor of a two-way causality between the share market returns and equity fund flows in US. Caporale et al. (2004) and Alexakis et al. (2005) also identify a bi-directional dynamic 
relationship between mutual fund flows and stock market returns in Greece, and Alexakis et al. (2013) document an asymmetric causal relationship between the two variables for the Japanese mutual fund market. Moreover, when the commodities future market is analysed, the results are again far from definite. Irwin and Sanders (2010), using weekly observations of flows in 22 commodity futures markets from June 2006 to December 2009, find no evidence of causality from flows to returns and argument that index funds did not cause a bubble in commodity futures prices. Based on their results, the authors conclude that regulatory proposals to limit speculation are not justified and could do more harm than good. Plantier (2012) also finds that weekly and monthly net flows into commodity mutual funds do not lead to future commodity price changes, showing, thus, evidence against the financialization hypothesis. The results in Hamilton and $\mathrm{Wu}$ (2015) and in Demirer et al. (2015) do not support either the commodity financialization hypothesis. Similarly, and in a recent paper, Levy and Lieberman (2016) also find no evidence of a significant causal relationship between flows and returns in the futures commodities market. However, Babalos et al., (2016) shows that bidirectional causality exitsts between commodity returns and flows (as well as their volatilities), when one allows for nonlinearity, and bases inference on a nonparametric causality-in-quantiles approach.

In this context, the objective of this paper is to analyse the causal relationship between institutional trading as reflected in US commodities fund flows and commodities markets' returns. While most of the empirical studies have analysed this relationship by using time domain-based linear Granger causality tests (Irwin and Sanders, 2010; Levy and Lieberman, 2016) and, to some extent, nonparametric tests (Babalos et al., 2016), the main contribution of this paper is the use of a wavelet coherency analysis in the time and frequency domains. Wavelet coherency and phase 
differences simultaneously evaluate how causalities between the two variables of concern fluctuate across frequencies and vary over time. This allows us to obtain shortterm (high-frequency) and long-term (low-frequency) relationships between the two series, and thus controls for potential nonlinearities and structural breaks in the relationship between the two variables, which in turn, are likely to render linear Granger causality tests invalid due to misspecification in the linear framework. While nonparametric causality test can accommodate for nonlinearities and regime changes, they are restricted to only time-domain, and hence, cannot distinguish among causality in short-, medium-, and long-run. In addition, unlike phase differences in wavelets used to analyze causality, nonparametric tests are not time-varying and hence much more limited compared to the wavelet approach. ${ }^{1}$ To the best of our knowledge, this is the first paper that uses a wavelet approach to explore the interplay between the commodities fund flows and the commodities market returns.

The layout of the rest of the paper is as follows: Section 2 describes the wavelet approach, while Section 3 presents the data and discusses the empirical results. Finally, Section 4 concludes.

\section{MeTHODOLOGY}

While wavelet analysis is closely related to Fourier analysis, the former, however, possesses certain advantages over the latter analysis. In particular, wavelet analysis conserves information in both time and frequency domains by conducting the estimation of spectral characteristics of a time series as a function of time (Aguiar-Conraria et al., 2008). Further, wavelet analysis applies for non-stationary or locally stationary series

\footnotetext{
${ }^{1}$ One advantage however, of the causality in-quantiles test, developed by Balcilar et al., (forthcoming), and used by Babalos et al., (2016), is that it can analyze causality at higher moments as well.
} 
(Roueff and Sach, 2011). In addition, wavelet coherency allows for a three-dimensional analysis, which considers the time and frequency elements at the same time, as well as the strength of the correlation between the time-series elements (Loh, 2013). In this way, we can observe both the time- and frequency-variations of the correlation between two series in a time-frequency domain. Consequently, wavelet coherency provides a much better measure of co-movement between variables, commodity returns and flows, in comparison to conventional causality and correlation analysis. Following the approach of Li et al. (2015), we estimate wavelet coherency by using the cross-wavelet and auto-wavelet power spectrums as follow:

$$
R_{x y}^{2}(\tau, s)=\frac{\left|S\left(s^{-1} W_{x y}(\tau, s)\right)\right|^{2}}{S\left(s^{-1}\left|W_{x}(\tau, s)\right|^{2}\right) S\left(s^{-1}\left|W_{y}(\tau, x)\right|^{2}\right.},
$$

where $S$ is a smoothing operator. ${ }^{2}$ This formula gives a quantity between 0 and 1 in a time-frequency window. Zero coherency indicates no co-movement between returns and flows, while the highest coherency implies the strongest co-movement between the two series. On the wavelet coherency plots, red colors correspond to strong co-movement whereas blue colors correspond to weak co-movement.

We cannot easily distinguish between positive and negative co-movements as the wavelet coherency is squared. Thus, we use the phase difference to provide information on positive and negative co-movements as well as the leading relationships between the two series. Bloomfield et al. (2004) characterizes the phase difference relationship between $x(t)$ and $y(t)$ such that:

$$
\phi_{x y}=\tan ^{-1}\left(\frac{\mathcal{J}\left\{s\left(s^{-1} W_{x y}(\tau, s)\right)\right\}}{\Re\left\{\left(s^{-1} W_{x y}(\tau, s)\right)\right\}}\right), \text { with } \phi_{x y} \in[-\Pi, \Pi] \text {, }
$$

\footnotetext{
${ }^{2}$ Without smoothing, the squared wavelet coherency is always equal to 1 at any frequency and time. Torrence and Compo (1998) show that smoothing in time or frequency increases the degrees of freedom of each point and increases the confidence of the wavelet spectrum.
} 
where $\mathcal{J}$ and $\mathfrak{R}$ equal the imaginary and real parts of the smoothed cross-wavelet transform, respectively.

A phase difference of zero reveals that the two underlying series move together, while a phase difference of $\pi(-\pi)$ indicates that two series move in the opposite directions. If $\phi_{x y} \in(0, \pi / 2)$, then the series move in phase (positively co-move) with $x(t)$ preceding $y(t)$. If $\phi_{x y} \in(\pi / 2, \pi)$, then the series move out of phase (negatively

co-move) with $y(t)$ preceding $x(t)$. If $\phi_{x y} \in(-\pi,-\pi / 2)$, then the series move out of phase with $x(t)$ preceding $y(t)$. Finally, if $\phi_{x y} \in(-\pi / 2,0)$, then the series move in phase with $y(t)$ preceding $x(t)$. Also, the phase difference can imply causality between $x(t)$ and $y(t)$ in both the time and frequency domains. In sum, wavelet analysis permits deeper understanding than the conventional Granger causality test, which assumes that a single causal link holds for the whole sample period, as well as at each frequency (Grinsted et al., 2004; Tiwari et al., 2013). For example, in wavelet analysis, if $x(t)$ precedes $y(t)$, then a causal relationship runs from $x(t)$ to $y(t)$ at a particular time and frequency ( $\mathrm{Li}$ et al., 2015).

\section{DATA AND EMPIRICAL RESUltS}

Data on US commodity funds' flows were collected from Morningstar database. Active and passive commodities funds offered for sale in the US specialize in the following sectors: Agriculture, Broad Basket, Energy, Industrial Metals, Miscellaneous, Precious Metals. To this end, starting from May of 1997 monthly data on aggregate inflows/outflows for US active and passive commodity funds and the relevant assets are available until August of 2015. Following relevant studies, fund flows are normalized 
by employing previous month's total assets. Since the focus of the present study is on the interaction between aggregate fund flows and commodities market returns, the monthly prices of the fully investable Standard and Poor's Goldman Sachs Commodity Index (S\&P GSCI hereafter) are also included. S\&P GSCI closing prices were sourced from Bloomberg database. The S\&P GSCI consists of the most liquid commodity futures on 25 different commodities sectors. Returns are calculated via the sequential difference of the natural logarithm of the closing prices of the S\&P GSCI, i.e.,

$$
R_{t}=\ln \left(P_{t} / P_{t-1}\right) \times 100
$$

where $P_{t}$ denotes the value of the index at month $t .^{3}$

The behavior of cash inflows and outflows in the commodity funds market and that of the S\&P GSCI-based returns for the analyzed period are plotted in Figures 1a and $1 b$.

\section{[Insert Figures 1a and 1b around here]}

We start off by presenting the summary statistics of the normalized fund flows and commodities market returns in Table 1. The results, based on the Jarque-Bera test, highlight that the normality hypothesis is not supported for either variable, with both variables depicting excess kurtosis, and returns being skewed to the left and flows to the right. Consequently, it is natural to expect that focusing on causality solely in terms of the conditional mean might be inadequate.

\section{[Insert Table 1 around here]}

\footnotetext{
3 We would like to thank Professor Vassilios Babalos of Technological Educational Institute of Peloponnese, Kalamáta, for kindly providing us with the data set used in the empirical analysis.
} 
Although the aim of the present study is to investigate the causality between flows and returns across time and frequency domains using wavelet, for the sake of completeness and comparability, we also conduct the standard linear Granger causality test based on a vector autoregressive model of order $p(\operatorname{VAR}(p))$. In our study, a lag order of 1 is determined using the Schwarz Information Criterion (SIC). We use 1 lag, since this is also in line with the predictive regression framework used in predicting returns of variables. The results of the linear Granger causality tests are reported in Table 2. The null hypothesis that commodity fund flows do not Granger-cause commodities market returns cannot be rejected, even at the 10 percent level of significance. In addition, we observe that commodities market returns do not contain any information for fund flows either, since the null hypothesis that commodities market returns do not Granger-cause commodity fund flows cannot be rejected as well at conventional levels of significance. These results are in line with those obtained in Irwin and Sanders and Levy and Lieberman (2016).

\section{[Insert Table 2 around here]}

In order to justify the use of the time-varying wavelet approach, we conduct tests of nonlinearity and structural breaks to detect misspecification of the VAR model. To assess the existence of nonlinearity, we apply the Brock et al. (1996, BDS) test on the residuals of an AR(1) model for commodities market returns and fund flows, and also to the residuals of these two equations in the VAR(1) model. As can be seen from Table 3, the null of iid residuals is strongly rejected for all cases, except for the residual in the AR(1) model of commodity returns under dimension of 2 . More importantly, however, for the VAR model depicting the relationship between returns and flows, there is strong evidence of uncaptured nonlinearity, which in turn, makes the results from the linear Granger causality tests unreliable. 


\section{[Insert Table 3 around here]}

Next, we turn to Bai and Perron's (2003) tests of multiple structural breaks, applied again to the $\mathrm{AR}(1)$ model of the two variables and the two equations of the $\operatorname{VAR}(1)$ model. The results are presented in Table 4 and highlight strong evidence of structural breaks in not only the individual processes of returns and flows, but also in the relationship between the two variables. Therefore, the results of the linear Granger causality tests based on the assumption of parameter stability over the entire sample cannot be taken from granted due to possible misspecification.

\section{[Insert Table 4 around here]}

Having established non-linearity and the existence of possible structural breaks in the data, we now proceed by discussing the results of the time-varying wavelet approach across various frequency domains. Note that, an additional advantage of the wavelet based approach is that, unlike standard Granger causality tests, we do not need to specify the lag-length that should be used in a VAR model. This is important, since it is known that causality test results can be contingent on the choice of number of lags. ${ }^{4}$ In the presence of nonlinearity and structural breaks, one can of course conduct timevarying or rolling-window versions of the standard Granger causality test. However, issues of lag-length, window size and the fact that the tests will still only be in the timedomain would remain. The results from the wavelet based approach have been presented in Figures 2 to 4.

\section{[Insert Figures 2-4 around here]}

\footnotetext{
${ }^{4}$ Realizing this, we conducted the linear Granger causality tests with 2 lags as chosen by the Akaike Information Criterion (AIC). The results suggested that flows do not Granger cause returns, but returns were found to cause flows at the 5 percent level of significance. However, when we tested for nonlinearity and structural breaks in the $\operatorname{AR}(2)$ and $\operatorname{VAR}(2)$ models, similar results to those reported in Tables 3 and 4 were found, implying that the results from the linear model cannot be completely relied upon. These results are available upon request from the authors.
} 
Note that, the color code for wavelet coherency ranges from blue (low coherency - close to zero) to red (high coherency - close to one). The first two cycles (1 3 and 3 6) are associated with the short-run (i.e., high-frequency bands), while the other two cycles (6 12 and 12 24) are trying to capture the medium- and long-run (i.e., low-frequency bands) relationships, respectively. From Figure 2, we observe strong and statistically significant correlation between returns and flows for the period of 2008 to 2011 across the 1 2 months frequency band; from late 2009 to late 2012 around the 3 months frequency cycle, and finally from mid-2014 to the end of the sample (2015M08) across the 2 months frequency cycle. Some evidence of relatively weaker, but significant coherence above the 1 month frequency cycle is also observed for the periods of 2000 and 2004. But overall, these two variables are found to be strongly significantly related in the short-run for the period 2008 and onwards. Given this, in Figures 3 and 4, we focus on the phase differences so as to analyze the causal relationship between the variables for the frequency cycles of 1 3 and 3 6 months, with returns ordered first and flows second. To understand these results easily, we report the summary of the time-varying causal relationships at the frequency cycles of $1 \sim 3$ and 3 6 months in Table 5, which can be summarized from Figures 3 and 4. First note that, across these two frequency cycles, the two variables co-move positively, as they are always in-phase. If we concentrate over the period of 2008 till 2015, i.e., the time-span over which these variables are most strongly correlated, we find that, flows have predicted returns till the end of 2012, and beyond that returns have led flows. In addition, if we look at the periods of weak wavelet coherence, i.e., 2000 and 2004, flows have predicted returns during the first period, while causality have been bidirectional in the latter period. However, unlike the linear Granger causality tests, we do 
detect evidence of significant causal relationships between returns and flows restricted over the short-run, i.e., especially, the 1 3 months frequency cycle.

\section{[Insert Table 5 around here]}

\section{CONCLUSIONS}

This study is the first one that examines causality between commodities market returns and commodities mutual fund flows in US using a wavelet approach based on monthly data covering the period of May 1997 to August 2015. The wavelet based approach allows us to analyse causal relationships between these two variables not only over time, but also across the frequency domain, with the latter being able to detect causality across various horizons, i.e., short-, medium- and long-run.

As is standard practice in the causality literature, we start-off using linear Granger causality tests, but fail to detect any evidence of causality in any direction. Tests of nonlinearity and regime changes, however, indicate that the linear model is misspecified, which in turn, motivates us to use the wavelet-based approach. Our results from the time and frequency domains indicate the following: (i) Returns and flows are related to one another significantly primarily in the short-run, i.e., 1 3 months frequency cycle. (ii) At this frequency, these two variables tend to co-move positively most strongly over the period of 2008 to 2015 , though, some relatively weaker evidence is also detected around the period of 2000 and 2004. (iii) Finally, from the point of view of causality, flows are found to predict returns till the end of 2012, while causality holding the other way round, i.e. from returns to flows till the end of the period from 2013. That is, our results are consistent with the financialization hypothesis till the end 
of 2012, while they are in line with the "smart money" hypothesis from 2013 to 2015 , primarily in the short run, i.e., 1 3 months frequency cycle. Overall, our results highlight the importance of adopting a time-varying approach across the frequency domain, instead of relying on standard linear Granger causality tests to make inferences between these two variables - as has been done in the literature in general. This is of paramount importance in terms of drawing correct conclusions, as the constant parameter linear model is misspecified in the presence of nonlinearities and structural breaks, and hence, cannot be relied upon. As an avenue for future research, it would be interesting to use the wavelet approach to analyse the relationship between stock market returns and equity fund flows. 


\section{References}

Aguiar-Conraria, L., Azevedo, N., Soares, M. J. 2008. Using wavelets to decompose the time-frequency effects of monetary policy. Physica A: Statistical Mechanics and its Applications 387, 2863-2878.

Alexakis, C. Niarchos, N., Patra,T. and Poshakwale, S. 2005. The dynamics between stock returns and mutual fund flows: empirical evidence from the Greek market. International Review of Financial Analysis 14, 559-569.

Alexakis, C., Dasilas, A., Grose, C. 2013. Asymmetric dynamic relations between stock prices and mutual fund units in Japan. An application of hidden cointegration technique. International Review of Financial Analysis 28, 1-8.

Babalos, V., Stravoyiannis, S., Gupta, R. 2015. Do commodity investors herd? Evidence from a time-varying stochastic volatility model. Resources Policy 46, 281 287.

Babalos, V. Balcilar, M., 2016. Does institutional trading drive commodities prices away from their fundamentals: Evidence from a nonparametric causality-in-quantiles test. Finance Research Letters. http://dx.doi.org/10.1016/j.frl.2016.11.017

Bai, J., Perron, P., 2003. Computation and analysis of multiple structural change models. Journal of Applied Econometrics 18, 1-22.

Balcilar, M., Bekiros, S., Gupta, R. Forthcoming. The role of news-based uncertainty indices in predicting oil markets: a hybrid nonparametric quantile causality method. Empirical Economics. 
Basak, S., Pavlova, A. 2016. A model of financialization of commodities. Journal of Finance, forthcoming.

Bloomfield, D. S., McAteer, R. J., Lites, B. W., Judge, P. G., Mathioudakis, M., Keenan, F. P. 2004. Wavelet phase coherence analysis: application to a quiet-sun magnetic element. The Astrophysical Journal 617, 623.

Brock, W., Dechert, D., Scheinkman, J., LeBaron, B., 1996. A test for independence based on the correlation dimension. Econometric Reviews 15, 197-235.

Caporale, G., Philippas, N., Pittis, N. 2004. Feedbacks between mutual fund flows and security returns: evidence from the Greek capital market. Applied Financial Economics 14, 981-989.

CTFC. 2008. Staff report on commodity swap dealers and index traders with commission recommendations. Commodity Futures Trading Commission (September).

Cheng, I.H., Xiong, W. 2014. Financialization of commodity markets. Annual Review of Financial Economics 6, 419-441.

Demirer, R., Lee, H-T., Lien, D. 2015. Does the stock market drive herd behavior in commodity futures markets? International Review of Financial Analysis 39, 32-44

Edelen, R., Warner, J. 2001. Aggregate price effects of institutional trading: a study of mutual fund flow and market returns. Journal of Financial Economics 59, 195-220.

Edwards, F., Zhang, X. 1998. Mutual funds and stock and bond market stability. Journal of Financial Services Research 13, 257-282. 
Fattouh, B., Kilian, L., Mahadeva, L. 2016. The role of speculation in oil markets: what have we learned so far? The Energy Journal, forthcoming.

Fernandez, V. 2015. Influence in commodity markets: Measuring co-movement globally. Resources Policy 45, 151-164.

Grinsted, A., Moore, J. C., Jevrejeva, S. 2004. Application of the cross wavelet transform and wavelet coherence to geophysical time series. Nonlinear Processes in Geophysics 11, 561-566.

Grubber, M.J. 1996. Another puzzle: the growth in actively managed mutual funds. Journal of Finance 51, 783- 810.

Hamilton, J. 2009. Causes and consequences of the oil shock of 2007-08. Brookings Papers on Economic Activity 1, 215-261.

Hamilton, J., Wu, J.C. 2015. Effects of index-fund investing on commodity futures prices. International Economic Review 56, 187-205.

Ippolito, R.A. 1992. Consumer reaction to measures of poor quality: Evidence from the mutual fund industry. Journal of Law and Economics 35, 45-70.

Irwin, S.H., Sanders, D.R. 2010. The impact of index and swap funds in commodity futures markets: Preliminary Results. OECD Food, Agriculture and Fisheries Papers 27.

Kilian, L. 2009. Not all oil price shocks are alike: Disentangling demand and supply shocks in the crude oil market. American Economic Review 99, 1053-1069.

Krugman, P. 2008. More on oil and speculation. New York Times, May 13.

Levy, A. and Lieberman, O. 2016. Active flows and passive returns. Review of Finance, forthcoming. 
Li, X. L., Chang, T., Miller, S. M., Balcilar, M., \& Gupta, R. 2015. The co-movement and causality between the US housing and stock markets in the time and frequency domains. International Review of Economics and Finance 38, 220-233.

Loh, L. 2013. Co-movement of Asia-Pacific with European and US stock market returns: A cross-time-frequency analysis. Research in International Business and Finance 29, 1-13.

Mosebach, M., Najand, M., 1999. Are the structural changes in mutual funds investing driving the US stock market to its current level? Journal of Financial Research 22, $317-329$.

Oh, N., Parwada, J., 2007. Relations between mutual fund flows and stock market returns in Korea. Journal of International Financial Markets, Institutions and Money $17,140-151$.

Plantier, L. C. 2012. Commodity Markets and Commodity Mutual Funds. ICI Research Perspective 18 (3), 1-32.

Remolona, E.M., Kleiman, P., Gruenstein, D. 1997. Market returns and mutual fund flow. Economic Policy Review 3, 33-52.

Roueff, F., Sachs, R. 2011. Locally stationary long memory estimation. Stochastic Processes and Their Applications 121, 813-844.

Sensoy, A., Hacihasanog, E., Nguyen, D.K. 2015. Dynamic convergence of commodity futures: Not all type of commodities are alike. Resources Policy 44, 150-160.

Shleifer, A. 1986. Do demand curves for stocks slope down? Journal of Finance 41, 579-590. 
Silvennoinen, A., Thorp, S. 2013. Financialization, crisis and commodity correlation dynamics. Journal of International Financial Markets, Institutions and Money 24, $42-65$.

Tang, K., Xiong, W. 2012. Index investment and the financialization of commodities. Financial Analysts Journal 68, 6.

Tiwari, A. K., Mutascu, M., \& Andries, A. M. 2013. Decomposing time-frequency relationship between producer price and consumer price indices in Romania through wavelet analysis. Economic Modelling 31, 151-159.

Torrence, C., Compo, G.P. 1998. A practical guide to wavelet analysis. Bulletin of the American Meteorological Society 79, 61-78.

Warther, V., 1995. Aggregate mutual fund flows and security returns. Journal of Financial Economics 39, 209-235.

Watson, J., Wickramanayake, J. 2012.The relationship between aggregate managed fund flows and share market returns in Australia. Journal of International Financial Markets, Institutions and Money 22, 451-472.

Zheng, L. 1999. Is money smart? A study of mutual fund investors' fund selection ability. Journal of Finance 54, 901-933. 
Table 1. Summary Statistics

\begin{tabular}{|l|l|l|}
\hline Statistic & $\begin{array}{l}\text { RETURNS } \\
(\text { Rets })\end{array}$ & $\begin{array}{l}\text { FLOWS } \\
(\text { Flows })\end{array}$ \\
\hline Mean & -0.0009 & 0.0344 \\
\hline Median & 0.0035 & 0.0165 \\
\hline Maximum & 0.1795 & 0.4982 \\
\hline Minimum & -0.3313 & -0.4677 \\
\hline Std. Dev. & 0.0683 & 0.0886 \\
\hline Skewness & -0.6397 & 1.3552 \\
\hline Kurtosis & 4.8508 & 13.9670 \\
\hline Jarque-Bera & 46.4065 & 1169.8680 \\
\hline Probability & 0.0000 & 0.0000 \\
\hline Observations & 220 & 220 \\
\hline
\end{tabular}

Note: Std. Dev. symbolizes the Standard Deviation; $p$-value corresponds to the test of normality based on the Jarque-Bera test

Table 2. Linear Granger causality test

\begin{tabular}{lcc}
\hline Null hypothesis & $\chi^{2}(1)$ test statistic & $p$-value \\
\hline Flows does not Granger cause Rets & 0.6395 & 0.4239 \\
Rets does not Granger cause Flows & 0.2563 & 0.6127 \\
\hline
\end{tabular}


Table 3. Brock et al. (1996) BDS test.

\begin{tabular}{lccccc}
\hline & \multicolumn{5}{c}{$M$} \\
\cline { 2 - 6 } & 2 & 3 & 4 & 5 & 6 \\
\hline AR(1): Rets & 0.8577 & 0.0029 & 0.0000 & 0.0000 & 0.0001 \\
AR(1): Flows & 0.0138 & 0.0004 & 0.0000 & 0.0000 & 0.0000 \\
VAR(1): [Rets, Flows] & 0.0160 & 0.0000 & 0.0000 & 0.0001 & 0.0064 \\
VAR(1): [Flows, Rets] & 0.0000 & 0.0000 & 0.0000 & 0.0000 & 0.0000
\end{tabular}

Note: See note to Table $2 ; m$ stands for the number of (embedded) dimension which embed the time series into $m$-dimensional vectors, by taking each $m$ successive points in the series. Value in cell represents the p-value of the BDS $z$-statistic with the null of i.i.d. residuals.

Table 4. Bai and Perron's (2003) test of multiple structural breaks

\begin{tabular}{ll}
\hline Models & \multicolumn{1}{c}{ Break Dates } \\
\hline AR(1): Rets & 1999M03, 2000M12, 2002M02, 2003M05, 2004M10, 2007M09, 2008M07, \\
& 2009M05, 2014M07 \\
AR(1): Flows & 1998M04, 1999M08, 2000M06, 2001M09, 2002M07, 2003M05, 2004M04, \\
& 2006M03, 2009M01, 2009M11 \\
VAR(1): [Rets, Flows] & 1999M03, 2000M12, 2001M12, 2007M09, 2008M07, 2009M05, 2010M03, \\
& 2011M05, 2014M07 \\
VAR(1): [Flows, Rets] & 1998M04, 1999M08, 2000M06, 2002M02, 2003M04, 2006M03, 2009M01, \\
& 2009M11, 2011M04
\end{tabular}

Note: See notes to Table 2. Break dates are based on the Bai and Perron (2003) test of multiple structural breaks applied to the AR(1) models of Rets and Flows and the equations of the VAR(1) model comprising of these returns. 
Table 5. Wavelet phase differences between returns and flows

\begin{tabular}{|c|c|c|c|}
\hline Frequency Cycle & Period & Phase & Causality \\
\hline \multirow[t]{7}{*}{$1 \sim 3$} & 1997M5-1998M9 & $\left(0, \frac{\pi}{2}\right)$, In-phase & Rets $\rightarrow$ Flows \\
\hline & 1998M10-2003M7 & $\left(\frac{-\pi}{2}, 0\right)$, In-phase & Flows $\rightarrow$ Rets \\
\hline & 2003M8-2003M10 & $\left(0, \frac{\pi}{2}\right)$, In-phase & Rets $\rightarrow$ Flows \\
\hline & 2003M11 & $\left(\frac{-\pi}{2}, 0\right)$, In-phase & Flows $\rightarrow$ Rets \\
\hline & 2003M12-2004M4 & $\left(0, \frac{\pi}{2}\right)$, In-phase & Rets $\rightarrow$ Flows \\
\hline & 2004M5-2012M11 & $\left(\frac{-\pi}{2}, 0\right)$, In-phase & Flows $\rightarrow$ Rets \\
\hline & 2012M12-2015M8 & $\left(0, \frac{\pi}{2}\right)$, In-phase & Rets $\rightarrow$ Flows \\
\hline \multirow[t]{4}{*}{$3 \sim 6$} & 1997M5-1997M11 & $\left(0, \frac{\pi}{2}\right)$, In-phase & Rets $\rightarrow$ Flows \\
\hline & 1997M12-1998M7 & $\left(\frac{-\pi}{2}, 0\right)$, In-phase & Flows $\rightarrow$ Rets \\
\hline & 1998M8 & $\left(0, \frac{\pi}{2}\right)$, In-phase & Rets $\rightarrow$ Flows \\
\hline & 1998M9-2015M8 & $\left(\frac{-\pi}{2}, 0\right)$, In-phase & Flows $\rightarrow$ Rets \\
\hline
\end{tabular}


Figure 1a. Plot of Standard and Poor's Goldman Sachs Commodity Index-Based Returns

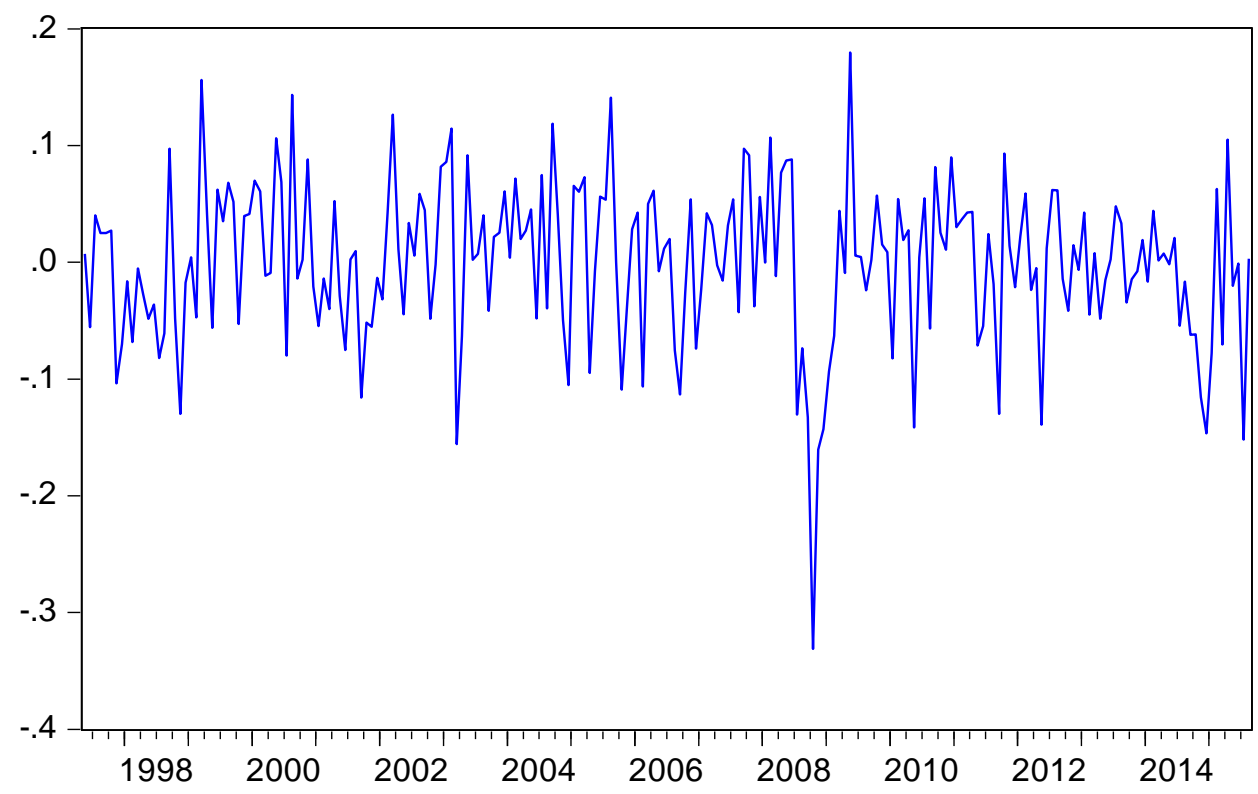

Figure 1b. Plot of Normalized Commodity Fund Flows

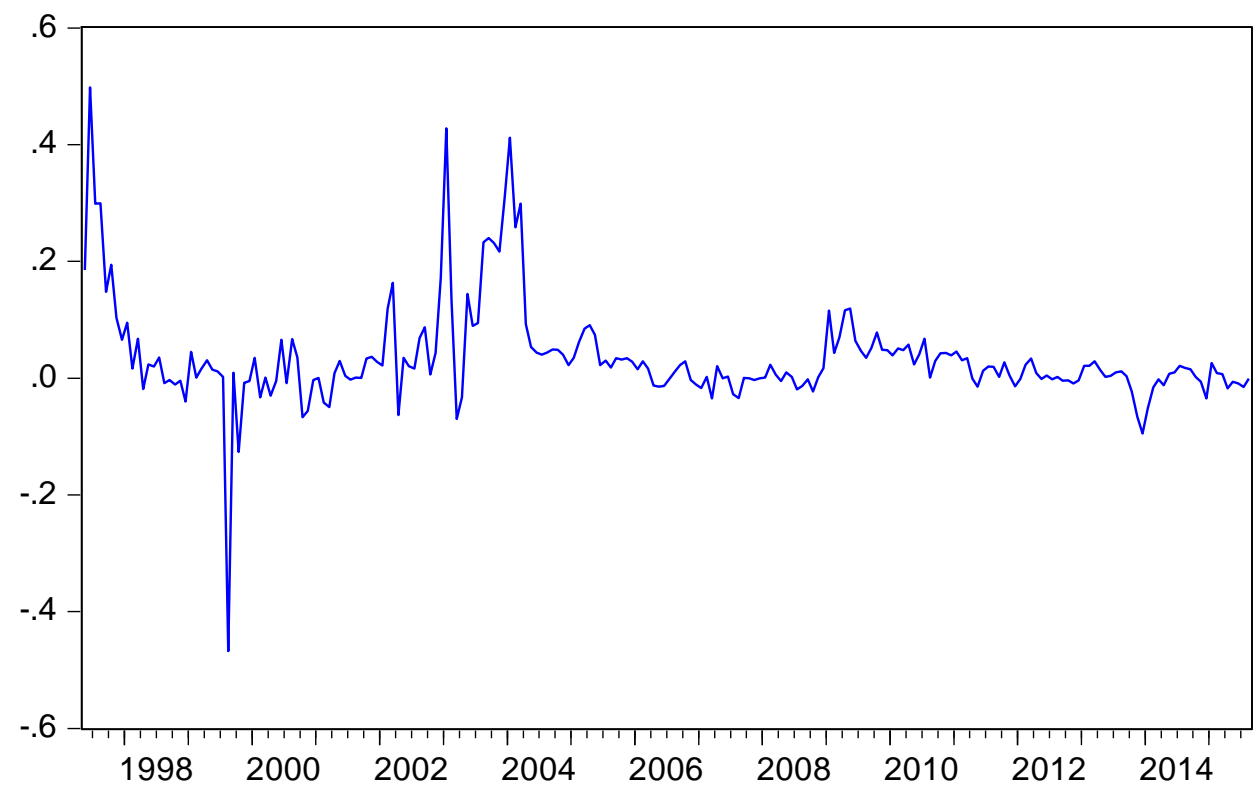


Figure 2. Wavelet Coherency between Returns and Flows

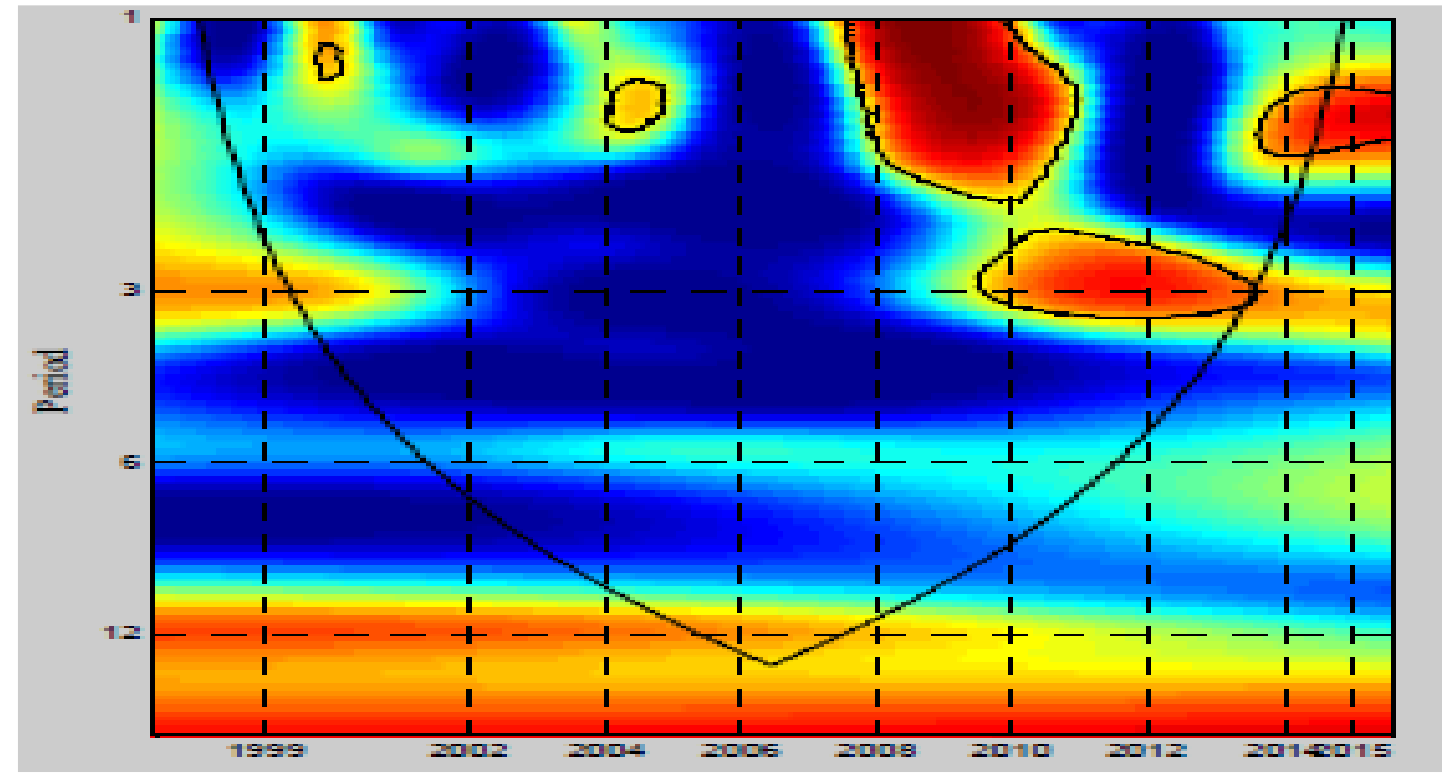

Figure 3. Phase Differences between Returns at flows at 1 3 Months Frequency Cycle

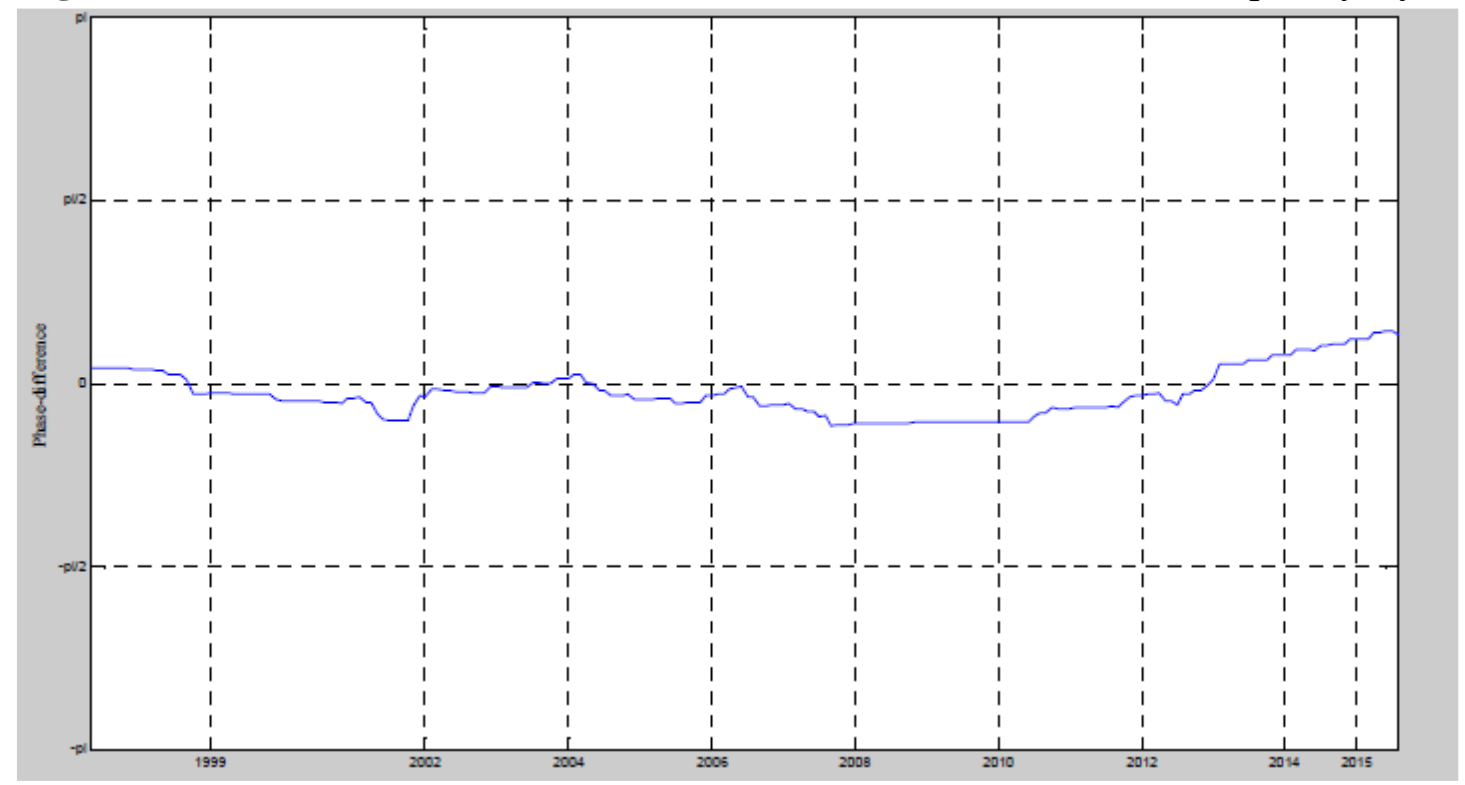


Figure 4. Phase Differences between Returns at flows at 3 6 Months Frequency Cycle

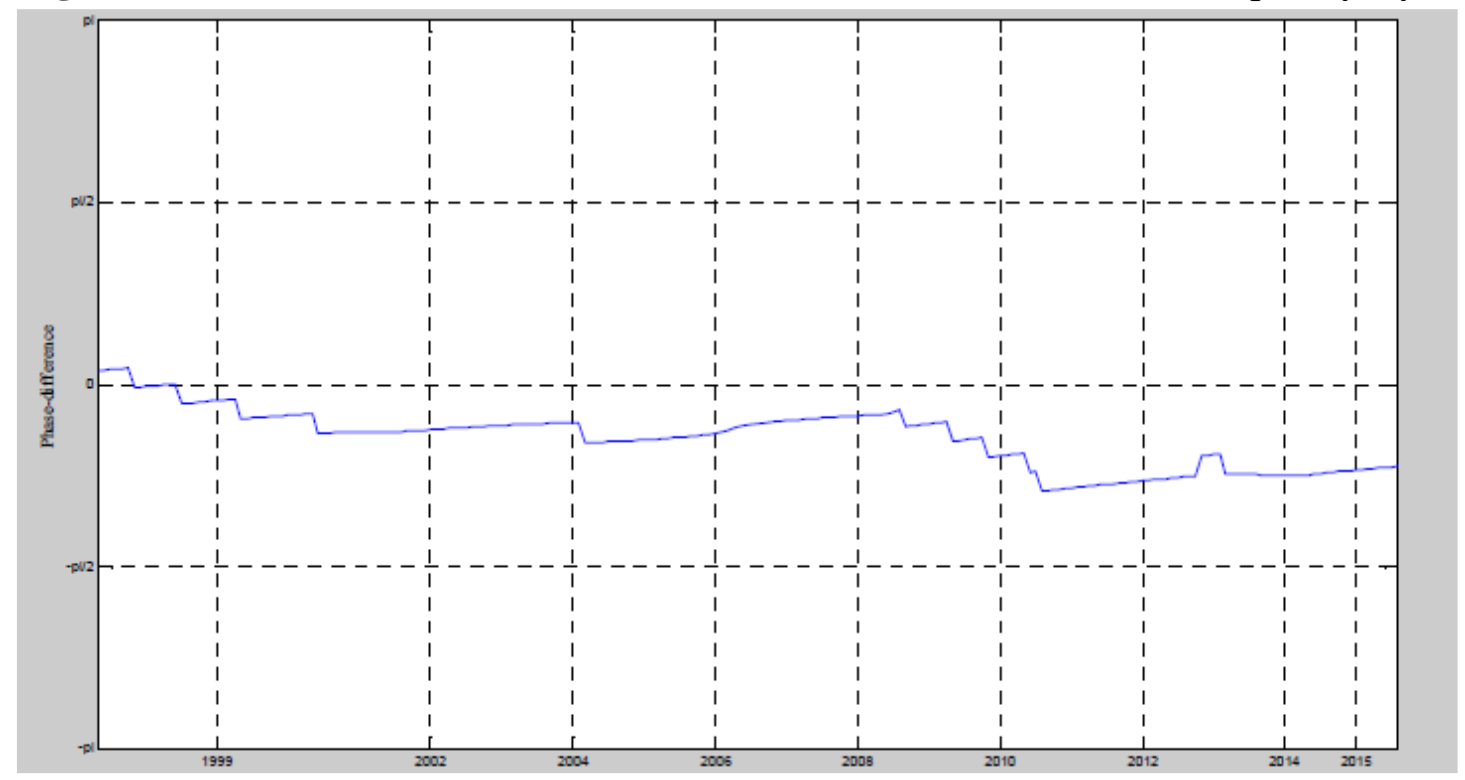

